NASA/TM-2003-212721

\title{
High Temperature Fusion Reactor Cooling Using Brayton Cycle Based Partial Energy Conversion
}

\author{
Albert J. Juhasz \\ Glenn Research Center, Cleveland, Ohio \\ Jerzy T. Sawicki \\ Cleveland State University, Cleveland, Ohio
}


Since its founding, NASA has been dedicated to the advancement of aeronautics and space science. The NASA Scientific and Technical Information (STI) Program Office plays a key part in helping NASA maintain this important role.

The NASA STI Program Office is operated by Langley Research Center, the Lead Center for NASA's scientific and technical information. The NASA STI Program Office provides access to the NASA STI Database, the largest collection of aeronautical and space science STI in the world. The Program Office is also NASA's institutional mechanism for disseminating the results of its research and development activities. These results are published by NASA in the NASA STI Report Series, which includes the following report types:

- $\quad$ TECHNICAL PUBLICATION. Reports of completed research or a major significant phase of research that present the results of NASA programs and include extensive data or theoretical analysis. Includes compilations of significant scientific and technical data and information deemed to be of continuing reference value. NASA's counterpart of peerreviewed formal professional papers but has less stringent limitations on manuscript length and extent of graphic presentations.

- TECHNICAL MEMORANDUM. Scientific and technical findings that are preliminary or of specialized interest, e.g., quick release reports, working papers, and bibliographies that contain minimal annotation. Does not contain extensive analysis.

- CONTRACTOR REPORT. Scientific and technical findings by NASA-sponsored contractors and grantees.
- CONFERENCE PUBLICATION. Collected papers from scientific and technical conferences, symposia, seminars, or other meetings sponsored or cosponsored by NASA.

- SPECIAL PUBLICATION. Scientific, technical, or historical information from NASA programs, projects, and missions, often concerned with subjects having substantial public interest.

- TECHNICAL TRANSLATION. Englishlanguage translations of foreign scientific and technical material pertinent to NASA's mission.

Specialized services that complement the STI Program Office's diverse offerings include creating custom thesauri, building customized databases, organizing and publishing research results ... even providing videos.

For more information about the NASA STI Program Office, see the following:

- Access the NASA STI Program Home Page at http://www.sti.nasa.gov

- E-mail your question via the Internet to help@sti.nasa.gov

- Fax your question to the NASA Access Help Desk at 301-621-0134

- Telephone the NASA Access Help Desk at 301-621-0390

- Write to:

NASA Access Help Desk

NASA Center for AeroSpace Information 7121 Standard Drive

Hanover, MD 21076 
NASA/TM-2003-212721

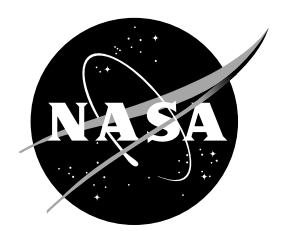

\title{
High Temperature Fusion Reactor Cooling Using Brayton Cycle Based Partial Energy Conversion
}

\author{
Albert J. Juhasz \\ Glenn Research Center, Cleveland, Ohio \\ Jerzy T. Sawicki \\ Cleveland State University, Cleveland, Ohio
}

Prepared for the

Space Technology and Applications International Forum (STAIF-2004) sponsored by the American Institute of Physics

Albuquerque, New Mexico, February 8-12, 2004

National Aeronautics and

Space Administration

Glenn Research Center 


\section{Acknowledgments}

This work was conducted at NASA GRC and the Cleveland State University, Department of Mechanical Engineering.

This report is a formal draft or working paper, intended to solicit comments and ideas from a technical peer group.

Available from

NASA Center for Aerospace Information 7121 Standard Drive

Hanover, MD 21076
National Technical Information Service 5285 Port Royal Road Springfield, VA 22100 


\title{
High Temperature Fusion Reactor Cooling Using Brayton Cycle Based Partial Energy Conversion
}

\author{
Albert J. Juhasz \\ National Aeronautics and Space Administration \\ Glenn Research Center \\ Cleveland, Ohio 44135 \\ E-mail: Ajuhasz@grc.nasa.gov \\ Jerzy T. Sawicki \\ Cleveland State University \\ Cleveland, Ohio 44115
}

\begin{abstract}
For some future space power systems using high temperature nuclear heat sources most of the output energy will be used in other than electrical form, and only a fraction of the total thermal energy generated will need to be converted to electrical work. The paper describes the conceptual design of such a "partial energy conversion" system, consisting of a high temperature fusion reactor operating in series with a high temperature radiator and in parallel with dual closed cycle gas turbine (CCGT) power systems, also referred to as closed Brayton cycle (CBC) systems, which are supplied with a fraction of the reactor thermal energy for conversion to electric power. Most of the fusion reactor's output is in the form of charged plasma which is expanded through a magnetic nozzle of the interplanetary propulsion system. Reactor heat energy is ducted to the high temperature series radiator utilizing the electric power generated to drive a helium gas circulation fan. In addition to discussing the thermodynamic aspects of the system design the authors include a brief overview of the gas turbine and fan rotor-dynamics and proposed bearing support technology along with performance characteristics of the three phase AC electric power generator and fan drive motor.
\end{abstract}

\section{INTRODUCTION}

Over the next few decades space based high temperature nuclear reactors, besides enabling interplanetary propulsion and ample power generation in deep space, will also provide the heat sources for systems where most of the output energy will be used in high grade thermal form. Yet such applications will still require that a fraction of the reactor supplied thermal energy be allocated for conversion to continuous electric power output. Planetary surface applications of such systems include high temperature multi-megawatt heat sources for chemical/metallurgical processing of indigenous ore materials for production of oxygen and materials of construction. To transport high grade heat $(>1500 \mathrm{~K})$ from the heat source to the chemical processing sites circulation pumps, compressors, or fans will require work energy which can be obtained by partial conversion of the high temperature thermal energy into electrical work energy.

For interplanetary propulsion applications using nuclear fission heated hydrogen propellant, also referred to as "nuclear thermal" (NT) propulsion, or applications based on future nuclear fusion technology as discussed here, the greater portion of the thermal energy will be applied to raise the temperature of the propellant. But to meet on-board electric power requirements and to provide the work energy required to circulate "reactor coolant," a part of the generated thermal energy will need to be transformed into electrical energy via an arbitrary conversion cycle.

In contrast to the above type of energy conversion systems, power plants designed to provide maximum electric power for planetary surface loads or "nuclear electric propulsion" (NEP) applications are based on energy conversion systems, in which all of the thermal energy is made available to a thermodynamic conversion cycle. As an example of a system of this type utilizing a "closed Brayton cycle" (CBC) power plant, the reader is referred to a report by Juhasz et al., 1993. It should be noted, that due to Second Law limitations, even though a large portion of the initial thermal energy is rejected by the conversion cycle, the heat is available at much lower temperatures than required for the chemical processing applications mentioned above. For multi-megawatt space based systems where the Brayton cycle reject heat is transferred to the space environment via thermal radiation, large radiating surface areas will be needed. 
The objective of this work is to describe a high temperature heat removal scheme for power and propulsion systems which require the major portion of their on-board generated thermal energy to be rejected directly to space while converting a small fraction of this thermal energy to electric power needed for thermal transport power requirements and various on-board energy demands.

\section{DISCUSSION}

In this paper a thermodynamic analysis of a Closed Brayton Cycle power system in a "partial energy conversion" (PEC) configuration is presented. Such a PEC scheme was utilized in a number of evolving conceptual designs of nuclear fusion propulsion systems. The latest of these concepts including a $2 \mathrm{MW}_{\mathrm{e}}$ fission heat source (high temperature pellet bed gas reactor, HTGR) coupled to a CCGT power system providing the electrical energy required for fusion system start-up via "high harmonic fast wave heating" of plasma was described in detail by Williams et al.., 2003. While the emphasis here is on the thermodynamic and heat transfer/rejection aspects of the fusion propulsion system, some of its main components are briefly highlighted in the context of their influence on the required thermal analysis.

\section{Fusion Reactor Overview}

The Magnetic Nozzle Section with a toroidal fusion reactor chamber is shown in Figure 1. To contain the high indicated divertor (reactor) plasma temperature, in excess of $4000 \mathrm{eV},\left(>10^{7} \mathrm{~K}\right)$, a superconducting YBCO (yttriumbarium cobalt) magnet with $12 \mathrm{TF}$ (toroidal field) and 7-PF (poloidal field) magnet coils is used to envelop the toroidal chamber. The TF coils of $\sim 9 \mathrm{~T}$ field strength are to provide the needed toroidal confinement, while the PF coils ensure plasma stability. After start-up the high plasma temperature is maintained by injection of $1 \mathrm{~g} / \mathrm{sec}$ of deuterium-helium 3 fuel pellets at $10 \mathrm{~km} / \mathrm{sec}$ by use of a rail gun mounted to the $240 \mathrm{~m}$ long spacecraft structure. Since YBCO maintains its superconductivity at temperatures to $\sim 80 \mathrm{~K}, \mathrm{LN}_{2}$ coolant flowing annular jackets around the coils was utilized. The tremendous temperature gradient between the plasma and the liquid nitrogen coolant for the magnetic coils is but one of the challenges for the thermal design.

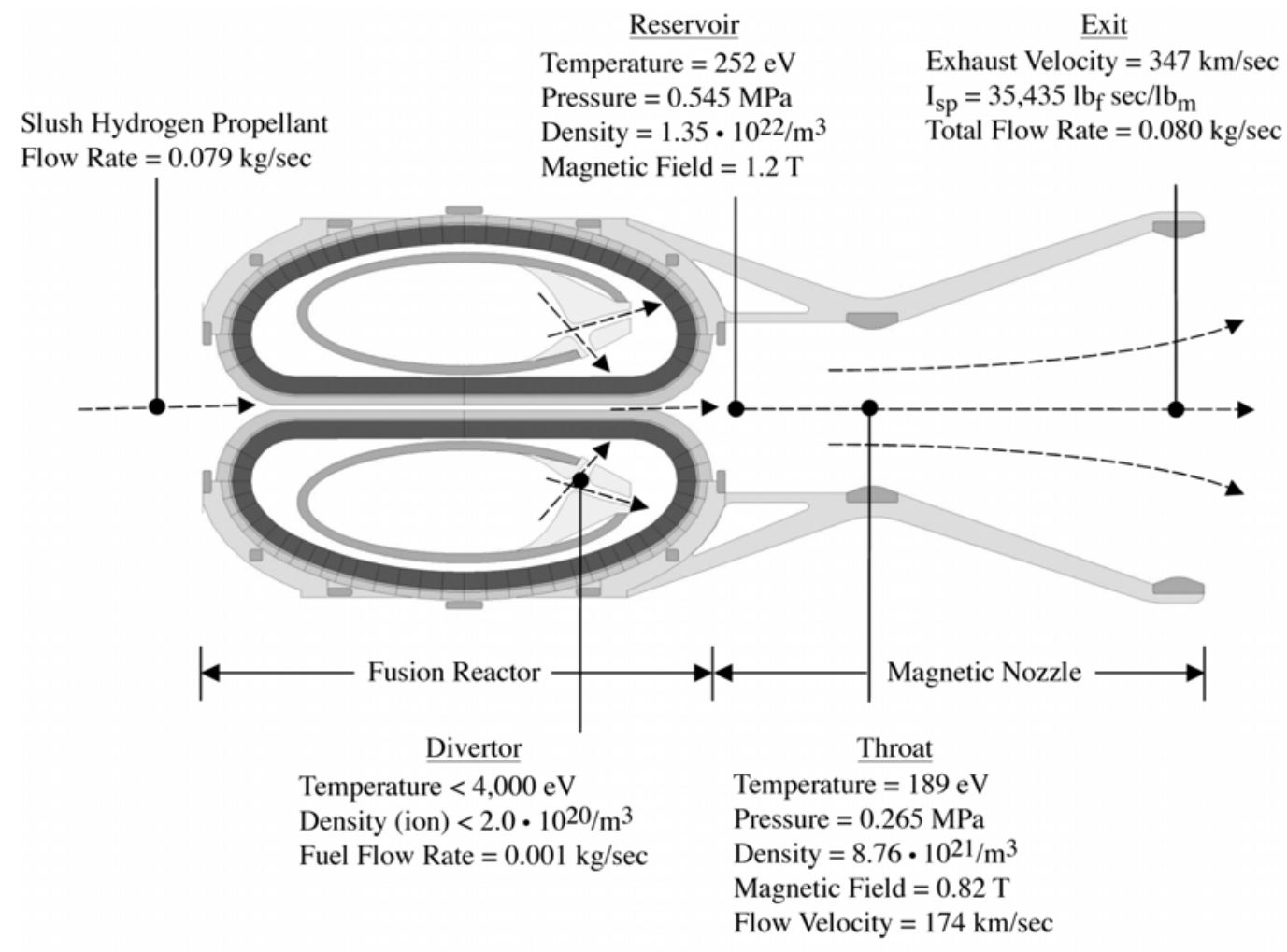

Figure 1. Fusion Reactor - Magnetic Nozzle Section. 
Thrust is provided by $0.079 \mathrm{~kg} / \mathrm{sec}$ of slush $\mathrm{H}_{2}$ propellant added to the $1 \mathrm{~g} / \mathrm{sec}$ fuel resulting in a total propellant flow rate of $0.080 \mathrm{~kg} / \mathrm{sec}$ which is heated to $\sim 250 \mathrm{eV}$ and accelerated via a magnetic nozzle. As shown, the propellant exhaust velocity is approaching $350 \mathrm{~km} / \mathrm{sec}$. The resultant thrust of approximately $13 \mathrm{kN}\left(\sim 2900 \mathrm{lb}_{\mathrm{f}}\right)$ implies a specific impulse of $3.5 \times 10^{5} \mathrm{~m} / \mathrm{sec}$, or $3.54 \times 10^{4} \mathrm{lb}_{\mathrm{f}} \mathrm{sec} / \mathrm{lb}_{\mathrm{m}}$. Considering the IMLEO vehicle mass of $1690 \mathrm{MT}$, the initial acceleration provided by the propulsion system will be about $0.8 \times 10^{-3} \mathrm{G}$. As propellant is gradually consumed during the mission the maximum acceleration/deceleration levels will nearly double.

\section{Energy Flow Considerations}

As shown in the energy flow diagram, Figure 2, the fusion reactor generates a total of about 7900 MW, i.e. $7895 \mathrm{MW}$, of charged particle and neutron energy. Although it is understood that the four digit accuracy in the energy balance values, being based solely on theoretical calculations, is beyond the control achievable in real systems, in the interest of clarity, energy flow values will be quoted exactly as they are shown in the figure.

A major portion of the reactor total, namely $6037 \mathrm{MW}$ is utilized directly in the magnetic nozzle in the form of deuterium and $\mathrm{He}$ ions (alpha particles), and protons and electrons to maintain the thrust power beam. Of the remaining nuclear radiation energy, $1858 \mathrm{MW}$, nearly two thirds, or $1215 \mathrm{MWt}$ was changed to heat (thermalized) by conversion of Neutron energy, Bremsstrahlung, and Synchrotron radiation. This thermalization was taking place at (a) the TF/PF Coils, (b) the Inboard Assembly, and (c) the First Wall. Unavoidable losses in the thermalization processes allowed for direct radiation of $643 \mathrm{MW}$ to be transferred to space by neutron emission (104 MW), Bremsstrahlung (272 MW), and Synchrotron radiation (267 MW). The next section will focus on the processing of the $1215 \mathrm{MWt}$ of thermal energy flow, or thermal power.

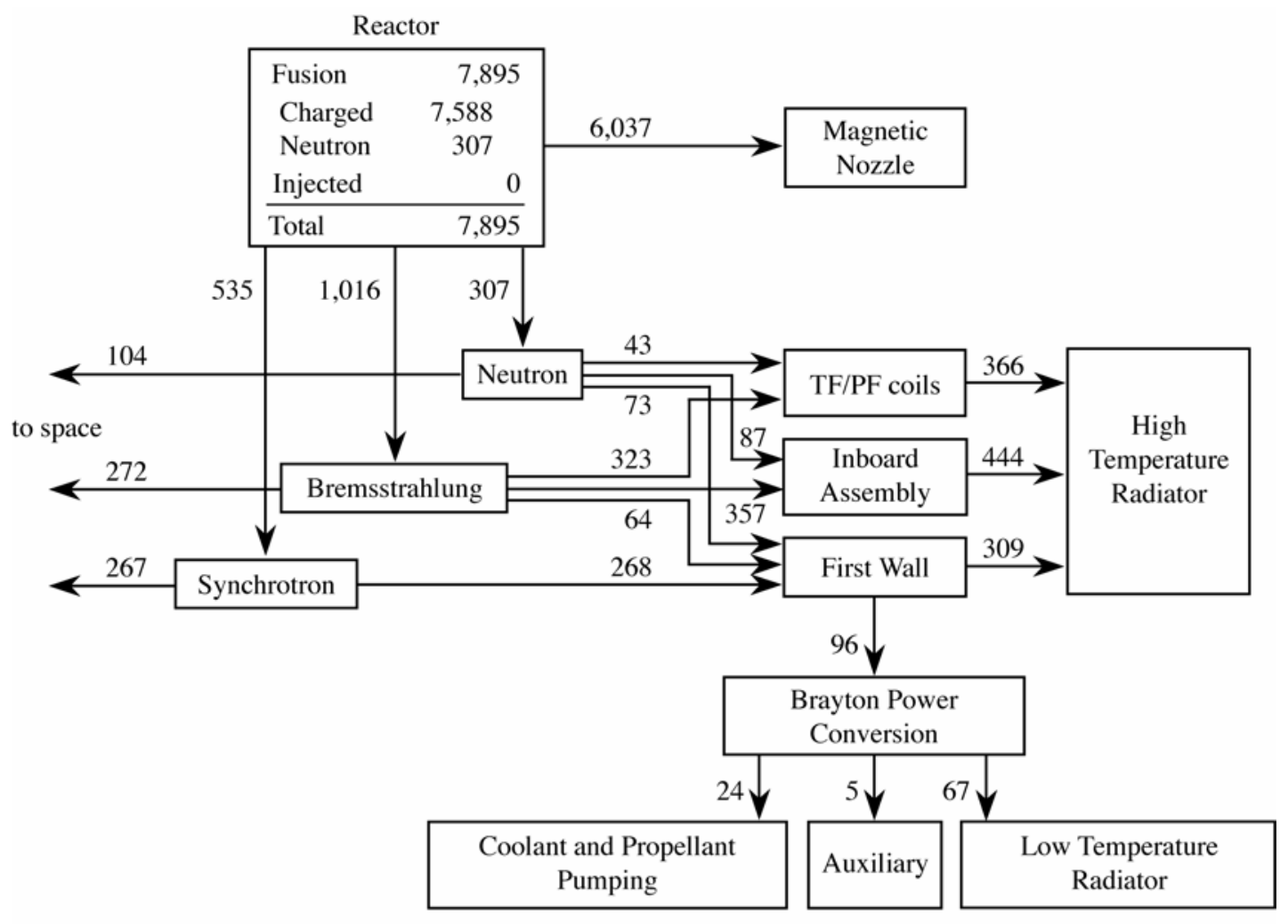

Figure 2. Energy Flow Diagram - (MW). 


\section{Fractional Energy Conversion and Reactor Cooling}

The thermal design challenge posed by high heat fluxes and temperature gradients was already pointed out above. High heat flux forced convection heat transfer resulting from high velocity gas flows through narrow flow passages resulted in reactor heat output of $1215 \mathrm{MWt}$ available at an exit He gas temperature of $1700 \mathrm{~K}$. Although conversion of the entire thermal energy available at approximately 31 percent efficiency would provide about 375 MWe for meeting electric power demand of a future planetary colony, the total on-board power requirement for the interplanetary spacecraft discussed here was only about 5 MWe. Moreover, generating 375 MWe via a nonregenerated CCGT energy conversion system with a $1700 \mathrm{~K}$ turbine inlet temperature and 31 percent thermal efficiency would require about $130,000 \mathrm{~m}^{2}$ of total radiator area. Using a regenerated cycle with 41 percent efficiency could lead to somewhat reduced radiator area and mass reductions in major subsystems. However, the added regenerator mass of about $80 \mathrm{MT}$ would negate any gains in overall system mass reduction. Thus for either cycle the mass penalty of at least 200 MT (metric tons) would severely impact the mission.

To resolve the problem it was decided to provide a high temperature fusion reactor cooling loop in parallel with two counter-rotating non-regenerated $\mathrm{CBC}$ power systems as shown in Figure 3. Of course this scheme requires that the thermal energy generated in each of the 12 reactor TF coils is equal, thereby insuring the same gas exit temperatures at each coil. This heat balance should also be reflected in the mass flow rate fractions through the coils. Mounting the two CCGT units, referred to as "turbosets," in a counter-rotating configuration achieves a cancellation of gyroscopic torques arising from the rotational inertia of the turbo-alternator rotors. The cycle layout, performance, and state points were generated by use of an enhanced version of the BRMAPS code generated by the author, and used previously for analysis of a $\mathrm{CBC}$ system with a high temperature pellet bed reactor heat source (Juhasz et al., 1993).

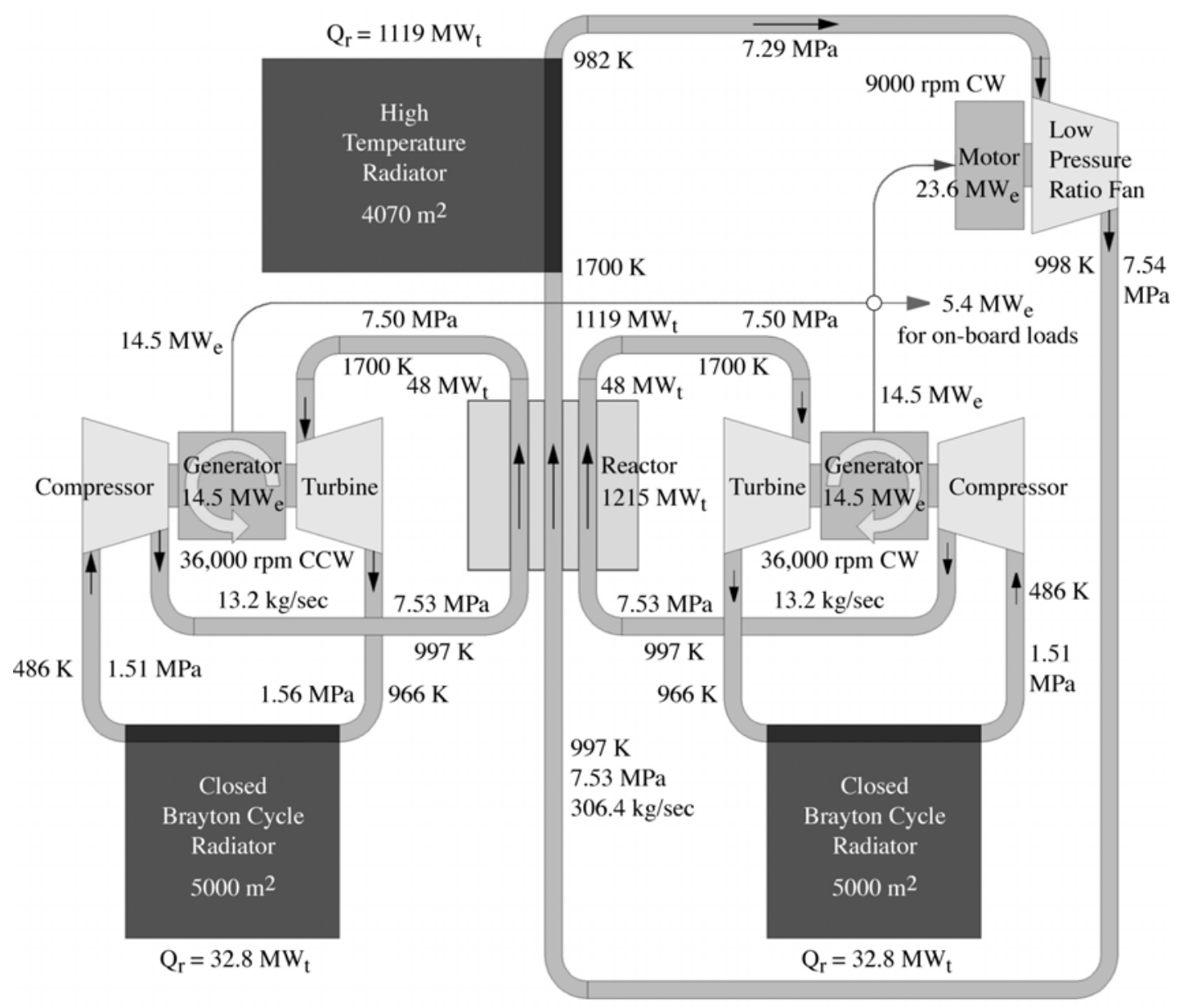

Figure 3. Heat Rejection and CBC Systems. 
The dual CCGT systems utilize about 95 to $100 \mathrm{MWt}$, about 1/12th of the total thermal power, equivalent to the heat output from one of the $12 \mathrm{TF}$ coils, to generate $29 \mathrm{MWe}$ electric power, of which $23.6 \mathrm{MWe}$ are supplied to a GHe fan drive motor. The remaining $\sim 5$ MWe power output are available for on-board housekeeping and miscellaneous energy requirements. The fan power requirement is dictated by the total reactor cooling flow $(306 \mathrm{~kg} / \mathrm{sec})$ and the fan pressure ratio which, in turn, is determined by the system pressure loss calculated at $\sim 3.7$ percent based on friction losses at flow Mach numbers of $\sim 0.25$. Note that the momentum pressure loss in the reactor is compensated by the momentum rise in the radiator cooling duct. The $\mathrm{CBC}$ reject heat of about $32.8 \mathrm{MWt}$ for each of the dual turbine power systems is transferred via the He cycle working fluid to the two CBC HP (heat pipe) radiators. To accommodate the large gas temperature drop from the $966 \mathrm{~K}$ radiator inlet temperature to the $486 \mathrm{~K}$ compressor inlet temperature a zoned heat pipe radiator design is used as proposed by Juhasz et al. (1993) and presented with additional detail in later publications (Juhasz, 2001 and Juhasz, 2002). A more detailed description of the CBC cooling scheme is given next.

As shown (Figure 3), the GHe low pressure ratio (1.04 to 1) fan circulates $306 \mathrm{~kg} / \mathrm{sec}$ of helium to provide for the major portion of the reactor heat removal $(\sim 1120 \mathrm{MWt})$. The fan output GHe stream at $997 \mathrm{~K}$ is ducted to the fusion reactor where it is equally split into parallel streams which absorb thermal energy from 11 of the $12 \mathrm{TF}$ coils. As indicated above, the 12th coil is cooled by the combined CBC compressor exit flows which also enter the reactor at $997 \mathrm{~K}$. The $12 \mathrm{TF}$ coil reactor coolant flows exit at $1700 \mathrm{~K}$. The flow from one TF coil is split and directed in equal amounts $(13.2 \mathrm{~kg} / \mathrm{sec})$ to the CBC turbines. But the major potion of the reactor cooling flow $(306 \mathrm{~kg} / \mathrm{sec})$ is ducted to the high temperature radiator. Inside central channels of this radiator the gas is forced to flow over the evaporator sections of Li heat pipes, whose external condenser sections on both sides of the central channels are provided with high thermal conductivity, high emissivity fins for rejecting heat to the space environment by thermal radiation. In the downstream portion of the radiator duct, where the He temperatures drop below $1300 \mathrm{~K}$, sodium and potassium heat pipes are used in a zoned HP radiator configuration as mentioned above.

Closer examination of Figure 3 also shows that the total radiator area, including 5,000 $\mathrm{m}^{2}$ for each of the two CBC power systems and $4070 \mathrm{~m}^{2}$ for the high temperature radiator, is approximately $14,100 \mathrm{~m}^{2}$. Thus the "fractional conversion" scheme requires an overall heat rejection radiator area which is only about 11 percent of the area quoted above. The reader should also note that the $4070 \mathrm{~m}^{2}$ of high temperature radiator is capable of rejecting over $1100 \mathrm{MWt}$, whereas the CBC radiators each require about $5000 \mathrm{~m}^{2}$, even though they only reject about $33 \mathrm{MWt}$. The obvious explanation is that the average surface temperature of the high temperature radiator is a factor of 2.4 higher than the average $\mathrm{CBC}$ radiator temperatures. And since the heat radiated, $\mathrm{Qr}$, is proportional to the fourth power of the radiating surface temperature, $\mathrm{Tr}$, the high temperature radiator will reject per unit area more than 33 times the heat rejected by the $\mathrm{CBC}$ radiators.

For the record, it should be mentioned, that the radiator areas quoted above include a redundancy factor of 1.2. This means that allowance is made for a 20 percent loss of heat rejection surface area due to micro-meteoroid punctures and miscellaneous orbital debris hazards during the life of the fusion propulsion system. The assumption is that only the finned heat pipe condenser sections which comprise the entire radiating surface area will be vulnerable to the hazards referred to above. Moreover each puncture takes out no more than the surface area associated with one heat pipe at a time. Of course there is no radiator loss of radiator area, if only the fin area is punctured and no heat pipe working fluid is lost. But the radiator area calculations also include the assumption of bumper protected central channels which carry the reactor cooling GHe and CBC working fluid helium flow. Table 1 summarizes salient performance parameters presented in this section.

TABLE 1. Coolant Systems Characteristics.

\begin{tabular}{lccc}
\multicolumn{1}{c}{ Parameter } & Design Value & Parameter & Design Value \\
\hline Number of coils & 12 & CBC generators & $3 \Phi \mathrm{AC}, 600 \mathrm{~Hz}$ \\
Superconductor material & YBCO & Fan motor & $3 \Phi \mathrm{AC}, 600 \mathrm{~Hz}$ \\
Pressure level, $\mathrm{MPa}$ & 7.5 & Fan power $\left(\mathrm{MW}_{\mathrm{e}}\right)$ & 23.6 \\
Cooling (working) fluid & $\mathrm{GHe}$ & Fan efficiency (percent) & 92 \\
Temperature, reactor in $(\mathrm{K})$ & 997 & Fan type & Axial, single stage \\
Temperature, reactor out $(\mathrm{K})$ & 1700 & Fan speed (rpm) & 9000 \\
Mass flowrate, radiator $(\mathrm{kg} / \mathrm{s})$ & 306 & System pressure loss (percent) & 3.7 \\
Mass flowrate, 2 CBC (kg/s) & 26.4 & CBC loop power (MW $\mathrm{MW}_{\mathrm{e}}$ & 14.5 \\
Radiator type & C-C heat pipe & CBC rotor speed (rpm) & 36,000 \\
High temperature radiator area $\left(\mathrm{m}^{2}\right)$ & 4070 & CBC radiator area (m) & 10,000 \\
Coolant system mass (MT) & 11 & CBC system mass (MT) & 30 \\
\hline
\end{tabular}




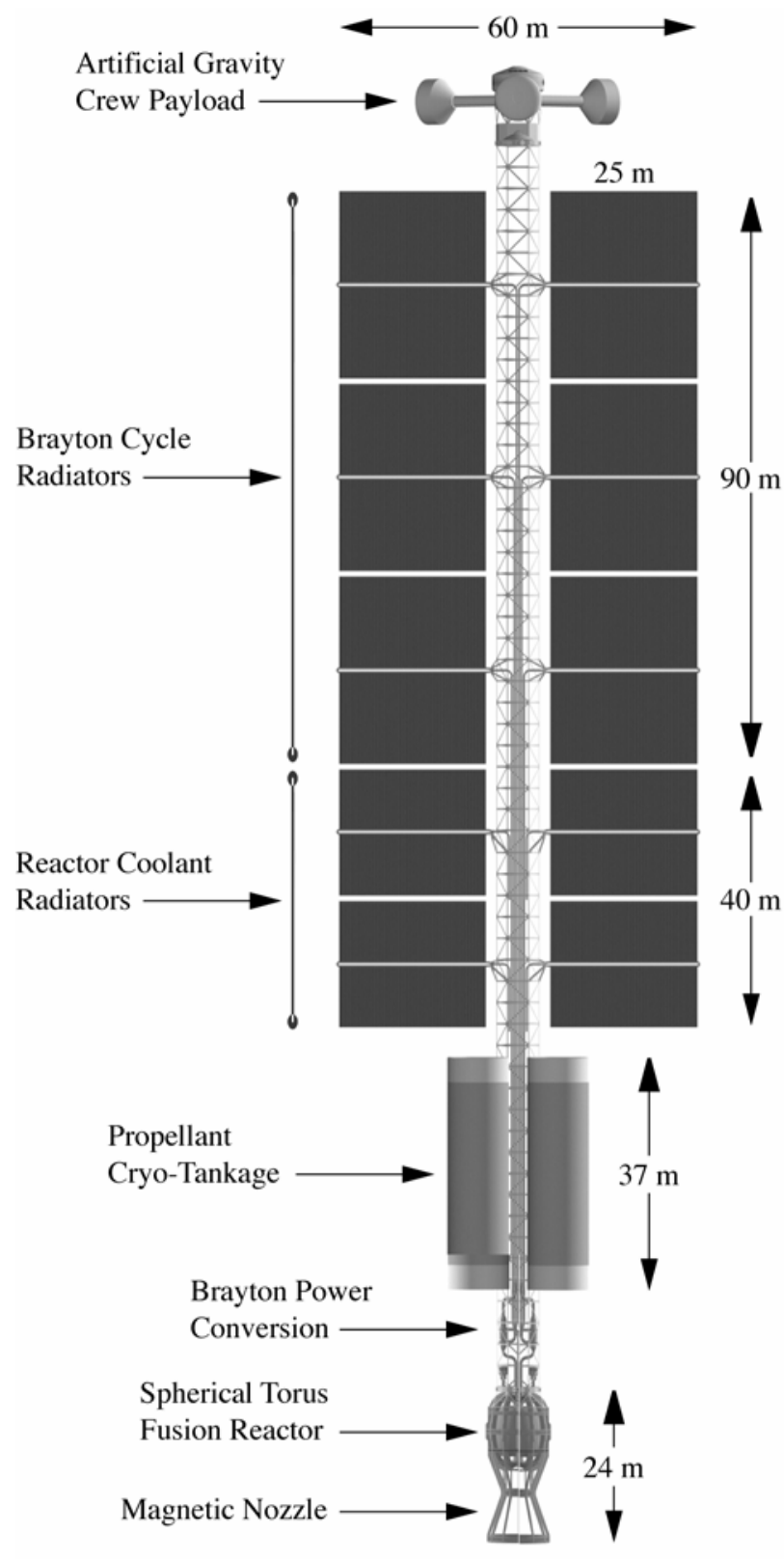

Figure 4. Dimensional Layout of Fusion Propulsion System.
An important observation regarding the characteristics and specifications for the $\mathrm{CBC}$ based cooling system is that even though the total radiator area with the fractional conversion was system was reduced significantly, the radiating surface area requirement still dominates the overall layout of the overall propulsion vehicle as shown in Figure 4. A central truss serves as the structural support for all major subsystems. Of the $240 \mathrm{~m}$ vehicle length between the crew compartment and the magnetic nozzle, the radiators account for more than half of the truss structure, and the $60 \mathrm{~m}$ vehicle width is set by the radiator area requirements.

Concerning the relatively high material surface temperatures $(\sim 1600 \mathrm{~K})$ existing at the radiator entrance area, and the much higher fusion reactor wall temperatures up to $1800 \mathrm{~K}$, use of refractory metal alloys engineering ceramics such as $\mathrm{SiC}, \mathrm{Si} 3 \mathrm{~N} 4$, and oxides of aluminum, zirconium, and magnesium are required. Even higher peak cycle temperatures $(\sim 2000 \mathrm{~K})$ should be enabled by $3 \mathrm{D}$ C-C (carbon-carbon) composites as reported by Hsu and Chen, 1989.

\section{Rotating Components}

Although the principal focus on this conceptual cooling scheme design for a high temperature fusion propulsion system has been on its thermal energy transfer and conversion aspects, it is understood that once the concept matures to the preliminary design stage, detailed attention will need to be devoted to the rotor dynamic and bearing support considerations, as presented in pertinent papers and textbooks in this field. Prime examples of textbooks in this discipline are (Vance, 1988) and (Adams, 2001). Stable, vibration-free rotor operation will require the latest developments in bearing technology, particularly magnetic bearings (Provenza et al., 2003) which offer lubrication-free high temperature service and built in health monitoring capability. With most of the development work on magnetic bearings focused on aircraft engine service at Earth gravity $(1 \mathrm{G})$ or higher environments, their lifetime reliability for the reduced $\mathrm{G}$ levels in space propulsion applications should be significantly higher. This would counteract the potentially longer rotor spans between bearing supports arising from the comparatively lower working fluid molecular weight of GHe machines, thus requiring the number of axial stages for a given pressure ratio to be higher than for aircraft propulsion plants which utilize working fluids consisting of air and hydrocarbon fuel combustion products. Fortunately the optimum pressure ratios for closed cycle GHe with turbine inlet temperatures up to $1700 \mathrm{~K}$ will be less than 3:1, and less than 6:1 for regenerated and non-regenerated cycles, respectively, whereas aircraft open cycle power plants (all non-regenerated) for wide body commercial transport planes may operate at pressure ration up to 40:1. Nevertheless rotordynamics and bearing design considerations will need to be incorporated along with thermodynamic and heat transfer aspects in generating a final design. 


\section{CONCLUSIONS}

In this paper a high temperature fusion reactor cooling system concept based on fractional conversion of the high temperature heat source to electrical energy was proposed. In this concept a sufficient fraction of the available thermal energy is converted to provide the necessary cooling fluid circulation for transporting the high grade heat to one or more high temperature radiators so it can be rejected to the space sink.

The energy conversion fraction can be tailored to provide additional electric power above that dictated by the cooling requirement for arbitrary on board applications. Using the cooling scheme proposed for the high temperature fusion reactor cooling application presented in this paper, radiating area requirements were reduced from over 130,000 square meters for an unneeded $375 \mathrm{MW}_{\mathrm{e}}$ system to 14,000 square meters for the system tailored to the particular application.

Planetary surface applications of the fractional energy conversion concept and its derivatives may include a variety of uses. Among these are chemical processing plants, metallurgical smelting and refinement of indigenous ores, and production of "life" supporting gases, including oxygen and hydrogen.

\section{REFERENCES}

Adams, Maurice L., Rotating Machinery Vibration, Marcel Dekker AG, Basel, Switzerland, 2001, pp. $27-109$.

Hsu, S.E. and Chen, C.I., The Processing and Properties of Some C/C Systems, Superalloys, Supercomposites and Superceramics, Academic Press, 1989, pp. 721-744.

Juhasz, Albert J., El-Genk, M.S.; and Harper, William B. "Closed Brayton Cycle Power System with a High Temperature Pellet Bed Reactor Heat Source for NEP Applications,” NASA TM-105933, Jan. 1993.

Juhasz, Albert J., "An Analysis and Procedure for Determining Space Environmental Sink Temperatures with Selected Computational Results,” NASA/TM-2001-210063, Jan. 2001.

Juhasz, Albert J., "Mathematical Analysis of Space Radiator Segmenting for Increased Reliability and Reduced Mass," NASA/TM-2001-210949, June 2001.

Juhasz, Albert J., "Design Considerations for Lightweight Space Radiators Based on Fabrication and Test Experience with a Carbon-Carbon Composite Prototype Heat Pipe,” NASA/TP-1998-207427/REV1, Sept. 2002.

Provenza, A.J., Montague, G.T., Jansen, M.J., Palazzolo, A.B., and Jansen, R.H., "High Temperature Characterization of a Radial Magnetic Bearing for Turbomachinery," Proceedings of ASME/GTI Turbo Expo 2003, June 16-19, 2003, Atlanta, GA.

Vance, J., Rotordynamics of Turbomachinery, Wiley, New York, 1988.

Williams, Craig H., Juhasz, Albert J., Borowski, Stanley K., and Dudzinski, Leonard A., "Space Propulsion via Spherical Torus Fusion Reactor," Fusion Science and Technology, vol. 43, no. 11, Jan. 2003, pp. 91-109. 
Public reporting burden for this collection of information is estimated to average 1 hour per response, including the time for reviewing instructions, searching existing data sources, gathering and maintaining the data needed, and completing and reviewing the collection of information. Send comments regarding this burden estimate or any other aspect of this collection of information, including suggestions for reducing this burden, to Washington Headquarters Services, Directorate for Information Operations and Reports, 1215 Jefferson Davis Highway, Suite 1204, Arlington, VA 22202-4302, and to the Office of Management and Budget, Paperwork Reduction Project (0704-0188), Washington, DC 20503.

\begin{tabular}{|l|l|l}
\hline 1. AGENCY USE ONLY (Leave blank) & $\begin{array}{c}\text { 2. REPORT DATE } \\
\text { December } 2003\end{array}$ & $\begin{array}{r}\text { 3. REPORT TYPE AND DATES COVERED } \\
\text { Technical Memorandum }\end{array}$ \\
\hline
\end{tabular}

4. TITLE AND SUBTITLE 5. FUNDING NUMBERS

High Temperature Fusion Reactor Cooling Using Brayton Cycle Based Partial Energy Conversion

6. AUTHOR(S)

WBS-22-706-87-02

Albert J. Juhasz and Jerzy T. Sawicki

7. PERFORMING ORGANIZATION NAME(S) AND ADDRESS(ES)

National Aeronautics and Space Administration

John H. Glenn Research Center at Lewis Field

Cleveland, Ohio 44135-3191

8. PERFORMING ORGANIZATION REPORT NUMBER

E-14238

9. SPONSORING/MONITORING AGENCY NAME(S) AND ADDRESS(ES)

10. SPONSORING/MONITORING AGENCY REPORT NUMBER

National Aeronautics and Space Administration

Washington, DC 20546-0001

NASA TM-2003-212721

\section{SUPPLEMENTARY NOTES}

Prepared for the Space Technology and Applications International Forum (STAIF-2004) sponsored by the American Institute of Physics, Albuquerque, New Mexico, February 8-12, 2003. Albert J. Juhasz, NASA Glenn Research Center; and Jerzy T. Sawicki, Cleveland State University, Cleveland, Ohio 44115. Responsible person, Albert J. Juhasz, organization code 5430, 216-433-6134.

12a. DISTRIBUTION/AVAILABILITY STATEMENT 12b. DISTRIBUTION CODE

Unclassified - Unlimited

Subject Category: 20

Distribution: Nonstandard

Available electronically at http://gltrs.grc.nasa.gov

This publication is available from the NASA Center for AeroSpace Information, 301-621-0390.

13. ABSTRACT (Maximum 200 words)

For some future space power systems using high temperature nuclear heat sources most of the output energy will be used in other than electrical form, and only a fraction of the total thermal energy generated will need to be converted to electrical work. The paper describes the conceptual design of such a "partial energy conversion" system, consisting of a high temperature fusion reactor operating in series with a high temperature radiator and in parallel with dual closed cycle gas turbine (CCGT) power systems, also referred to as closed Brayton cycle (CBC) systems, which are supplied with a fraction of the reactor thermal energy for conversion to electric power. Most of the fusion reactor's output is in the form of charged plasma which is expanded through a magnetic nozzle of the interplanetary propulsion system. Reactor heat energy is ducted to the high temperature series radiator utilizing the electric power generated to drive a helium gas circulation fan. In addition to discussing the thermodynamic aspects of the system design the authors include a brief overview of the gas turbine and fan rotor-dynamics and proposed bearing support technology along with performance characteristics of the three phase AC electric power generator and fan drive motor.

14. SUBJECT TERMS

Space power; Nuclear heat sources
15. NUMBER OF PAGES

13

16. PRICE CODE

\begin{tabular}{|c|c|c|}
\hline $\begin{array}{c}\text { 17. SECURITY CLASSIFICATION } \\
\text { OF REPORT } \\
\text { Unclassified }\end{array}$ & $\begin{array}{c}\text { 18. SECURITY CLASSIFICATION } \\
\text { OF THIS PAGE } \\
\text { Unclassified }\end{array}$ & $\begin{array}{c}\text { 19. SECURITY CLASSIFICATION } \\
\text { OF ABSTRACT } \\
\text { Unclassified }\end{array}$ \\
\hline
\end{tabular}

NSN 7540-01-280-5500

Standard Form 298 (Rev. 2-89)

Prescribed by ANSI Std. Z39-18 298-102 